\title{
LEPROSY IN BASUTOLAND
}

\section{The Country and the People}

Basutoland is a small mountainous country surrounded by the South African Union on every side. The main part of the country consists of high mountains and valleys in which communications are difficult; but there is a strip of plain along the west side where most of the population resides, and east of this on the way to the mountains is a plateau indented by the plain.

Basutoland is one of the three Crown Protectorates under the High Commissioner. The population is just over half a million. There is a Paramount Chief and sub-chiefs who rule the country in consultation with the Resident Commissioner and other British officers. The tribal system is considerably stronger than obtains in the Union with the exception of the native reserves.

Many diseases, such as malaria, hookworm, bilharzia, which in other parts of Africa predispose to leprosy, are absent or rare in Basutoland; but as elsewhere venereal diseases and scabies are common. On the whole the nourishment of the people is fairly good, but there is seasonal malnutrition when certain food stuffs are difficult to obtain.

\section{FREQUENCY OF LEPROSY}

Most of the information in this paragraph is culled from the report prepared by Dr. Germond for the Sir Alan Pym Commission. Leprosy is said to have been unknown in Basutoland before the Griqua immigration about 1840 . It is possible that up till then tribal control kept it in check, as leprosy is a disease connected with loosening of tribal control. A survey in I89I showed 200 lepers, but there may have been many more.

In I9I4 a form of compulsory segregation was initiated, and the Botsabelo leper settlement was begun with 657 patients gathered in six months with the help of the chiefs. In I9I4 there was rioting, and 245 patients deserted; it took I5 years for the numbers in the settlement to rise again to what they were originally. In I929 two native inspectors were appointed and later four others, one being placed in each of the six districts.

The following table gives the general statistics of patients for the first 20 years :-

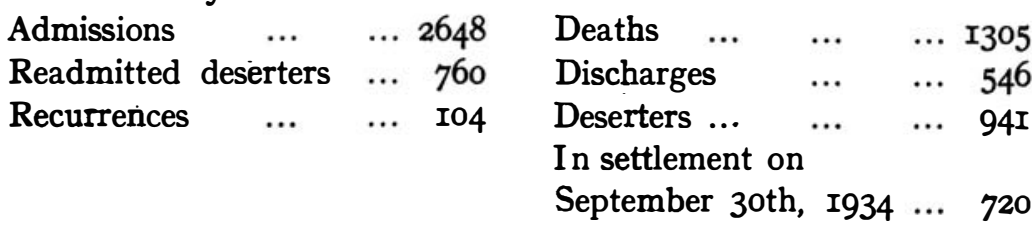


Admissions have varied in number from time to time according to the vigour of the efforts made to reach patients, the number and efficiency of native leprosy inspectors, etc. Recently it appears that the numbers are decreasing due to diminution of the frequency of leprosy.

\section{The Compulsory System}

The most suitable method of leprosy control varies in each country according to such factors as the size and nature of the country, the concentration of the whole and of the leprous population, facilities for transport, the advancement of education, the nature of the government and the number of the medical officers available. As Basutoland is surrounded by the Union of South Africa in which lepers are compulsorily segregated, it was inevitable that a certain amount of compulsion should be used. The method employed in Basutoland is perhaps wrongly called " compulsory "; it is rather a form of paternal moral suasion. This is shown by the fact that only on very few occasions has it been necessary to invoke the law in persuading patients to enter the settlement.

A suggestion has been made that able-bodied lepers of the non-infectious type should be segregated in small leper villages and treated by District Medical Officers; but experience elsewhere shows that without adequate supervision such camps are not a success, and that it would be exceedingly expensive to obtain this supervision; moreover the treatment in such villages, under existing circumstances, could not be nearly as good as at Botsabelo. Concealment is the chief disadvantage of compulsion, but this is being overcome : (I) by more efficient and better trained native leprosy inspectors; (2) by occasional surveys in limited areas; (3) by providing motor transport and thus facilitating the journey to the settlement; (4) by making the settlement more attractive socially, and speeding up the recovery and discharge of milder cases by more efficient treatment. On the whole I consider that under the circumstances the present method of recruiting patients is the best possible for Basutoland.

On the other hand I would suggest some modifications in the system in force for examining, treating and discharging patients :-

(I) A distinction 'might be made between the two main types of leprosy in examining patients for discharge. All cases should be examined bacteriologically on admission. Those which are negative and distinctly of the neural type with tuberculoid lesions need not be re-examined bacteriologically as long as they show no clinical signs of deteriorating into lepromatous cases. Strongly positive advanced lepromatous cases need not be re-examined until 
they show signs of reaching the negative stage. These omissions would save considerable time.

(2) When a formerly bacteriologically positive case gives a negative finding the examinations should as a rule be repeated at the same sitting, up to ten smears being taken from the skin in different parts of the body, and from the nose, until a positive is found. If these all prove negative he may be pronounced negative at that sitting, but similar examinations should be repeated at three month's intervals for one or two years, or even longer, depending on the former severity of the case and the speed at which it cleared up.

(3) I would suggest using the iodide test, regulated by the sedimentation test, in suitable cases as a further assurance that the patient is bacteriologically negative (see Leprosy, Diaynosis, Treatment and Prevention, 6th edition).

(4) The milder type of neural case, with few tuberculoid lesions and with little or no deformity, in which the clinical signs clear up rapidly under treatment, might be discharged after a shorter probationary period but not less than a minimum of six months after admission.

(5) At present the examination of the mucous membrane of the nose is the chief criterion of positive bacteriological findings. I suggest that the most outstanding lesion of the skin be first examined, and that in cases with generalised flat diffuse infiltration of the skin the lobule of the ear be chosen. If repeated examinations of the skin in different parts of the body prove negative, the nasal mucosa should be examined. Fallacies are more frequent in nose than in skin examination due to the presence of partially acid-fast saprophytes in the former. The nose is seldom found positive until after fairly wide-spread lepromatous infiltration of the skin.

(6) I consider that the above recommendations, if carried out, would accelerate the discharge of a large proportion of the milder cases, without increasing the danger of relapse, and thereby popularise the treatment and attract patients. The change in the method of examination of the severer lepromatous cases would ensure fewer relapses from among that type.

\section{Botsabelo Settlement}

Staff. This consists of a medical superintendent, a medical officer, a clerk, a compound manager, a farm bailiff, an artizan, a matron, a nursing sister. The African staff includes 8 leprosy inspectors, an interpreter, 3 dispensers, 2 female nurses, a chief guard, Io guards, a mechanic, a mason, a carpenter, II labourers. 
Patients. One of the most striking features noticed was the excess of female over male patients; this is contrary to the findings in most countries. The following table shows the relative number of the sexes in the settlement over several years :

\begin{tabular}{|c|c|c|c|}
\hline & & Males & Females \\
\hline May, & 1930 & 299 & $36 \mathrm{I}$ \\
\hline ", & 1932 & 345 & 368 \\
\hline ", & I933 & 355 & 383 \\
\hline ", & I934 & 352 & 376 \\
\hline$\because$ & 1935 & 345 & 381 \\
\hline June, & 1938 & 322 & 365 \\
\hline ," & 1939 & 342 & 406 \\
\hline
\end{tabular}

I had an opportunity of examining the 54 women patients admitted in the previous twelve months and found 57 per cent to be of the milder neural type with only five deformed; and 43 per cent of the severer lepromatous type with only one deformed. The examination of the 16 men admitted in the last three months showed only 38 per cent neural of which half were deformed. Thus, although there are more female patients than men, the former appear on the whole to have the milder type, though the small number of men examined is not adequate to form an opinion.

The reason for this unusual finding of excess of females over

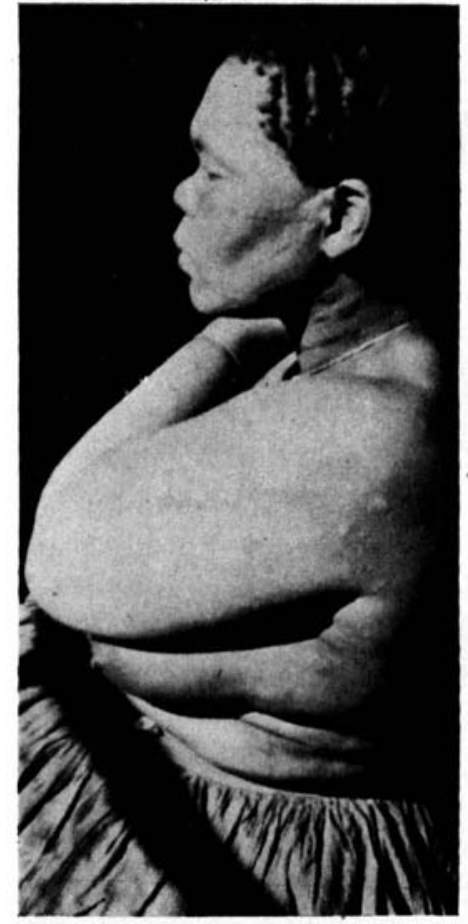

FIG. 6.

In Basutoland obesity may predispose to leprosy among women. males is difficult to explain, especially as males are more frequently medically examined than females at centres of mine recruitment, and are thus less liable to escape detection. A possible explanation is the less active and more sedentary life of the women witnessed to by their obesity and flabbiness as compared with the men (fig. 6).

Social Organisation. As in many other similar institutions the paramount importance of the organisation of the social life of the leper has not yet been fully realised and no provision is made for it in the budget. The leper differs from other patients in three essential ways: he is not a free agent; he has to spend years instead of days in the institution; he is not as a rule confined to bed and does not feel seriously ill, so that his nature calls out for a normal social life like that of a healthy person. Too often the Government leprosy institution, while spending lavish sums on staff, equipment, 
food and clothing, fails to provide for this basal need which is at the foundation of all success in anti-leprosy work and treatment; discipline, and the recovery of the patient are accordingly hampered. The Botsabelo settlement is particularly fortunate in its present superintendent and matron who, with the help of Miss Johnson, have taken a keen interest in and organised the social side; but the authorities would do well to follow the example of some of the best mission-controlled institutions and appoint permanent workers who would attend to this aspect of the work. The need is particularly clamant among the women and the children, and attention to this need might help to solve the problem referred to later under sex segregation and children.

Special Treatment. I have suggested substituting Hydnocarpus wingtiana oil with 4 per cent creosote for the iodised esters at present used. The oil when obtained from a reliable Indian firm (such as the Ernakulum Trading Company, Ernakulum, S.W. India) is more stable and less irritant than the esters, and the price is very much less. The disadvantage of its greater viscosity may be overcome by injecting as hot as it can be tolerated.

Intradermal injections in tuberculoid lesions should be given beyond the apparent edge. In several instances lesions were found to have spread beyond the marks of former injections. Iodised esters produce more or less permanent marks which, though not objected to by the patients, yet hide the lesion and make it difficult to assess progress of the healing process.

In assessing the tolerance of lepromatous cases for hydnocarpus injections the regular and repeated use of the sedimentation test is invaluable.

Accompanying Diseases. As mentioned above the usual predisposing and accompanying diseases are absent with the exception of scabies and venereal diseases. I suggest that the Kahn or other similar test should be used in every case.

Deterioration of Resistant Cases. Some leprologists have questioned whether the neural type with distinct tuberculoid lesions ever degenerates into the more severe lepromatous type. In the Pretoria leprosarium I saw a number of such cases, and I also noticed a small number of these among the few patients I examined at Botsabelo. This is a matter which calls for careful investigation as to its frequency, its cause and whether it occurs more frequently inside or outside the settlement. There is as a rule a distinct " threshold" between the two types, and it probably requires a marked deterioration of general resistance, from whatever cause, to permit passing of the threshold from one type to the other (see Leprosy Review, October, I939, p.225). 
Laboratory Work. The suggestions made above with special reference to bacteriological examinations, sedimentation tests and Kahn tests imply considerably more laboratory work. This would be made possible by the appointment of two trained African laboratory assistants who would work under the supervision and direction of the doctors.

Sex Segregation and Children. In a settlement where a certain amount of compulsion has been used in recruiting the patients it is difficult to enforce strict discipline with regard to 1solation of the sexes, and the rules in force are sometimes broken in spite of supervision. Thus a certain number of children are born in the settlement. Organisation of the social life of the settlement and especially of the women referred to above might help to solve this problem. It is a serious matter when it is remembered that children are more susceptible to infection than adults unless separated from infectious parents at birth. It has long been felt that a creche is necessary for children born in the settlement and for healthy children brought in by leper mothers. A voluntary creche is at present under construction at a distance of about 80 miles from the settlement; it will be run by the late matron of the settlement; children are to be admitted only if so desired by the parents, but there is reason to believe that they will cooperate. While it is hoped that this will to a certain extent meet the situation there should be, as elsewhere, a creche associated with and within easy access of the settlement, and under the same direction as the settlement.

Another matter worthy of mention is the isolation of young children with slight leprous lesions from infectious lepers; otherwise superinfection may take place and a mild case be changed into a more severe one.

\section{General Rfmarks}

The Basutoland Government is to be congratulated on its antileprosy campaign as it has gradually developed into its present form. Excellent work has been done by its past and present staff. A sum of about $£ \mathrm{I} 8,000$ a year is spent on the settlement and the leprosy inspectors. There are definite signs that at last the disease is being brought under control. One of the difficulties in finally accomplishing this may be the less stringently applied rules in some parts of the Union. It would be unwise for many years to come to relax in any way the present system; and from time to time such additions should be made as careful investigations show to be necessary. 